\title{
Suppression of ZnO Nanowire Formation in High Temperature Oxidation by Sandblasting Brass
}

\author{
Lu Yuan and Guangwen Zhou* \\ Department of Mechanical Engineering and Multidisciplinary Program in Materials Science and Engineering, \\ State University of New York, Binghamton, NY 13902, USA
}

\begin{abstract}
By exerting sandblasting onto brass $\left(\mathrm{Cu}_{0.7} \mathrm{Zn}_{0.3}\right)$ substrates, we show that the increased sandblasting can gradually suppress $\mathrm{ZnO}$ nanowire formation during the thermal oxidation of the $\mathrm{Cu}-\mathrm{Zn}$ alloy. Detailed surface composition analysis by EDS and depth-resolved XPS shows that both ZnO and CuO form initially on the surface upon oxidation but the $\mathrm{CuO}$ phase decreases from the surface to the subsurface region. It is shown that sandblasting leads to more even chemical composition of the brass substrate, which results in more uniform formation of the $\mathrm{CuO}$ phase across the surface. The subsequent reduction of the less stable CuO phase by $\mathrm{Zn}$ in the coalesced oxide layer results in uniformly accumulated pure $\mathrm{Cu}$ in the subsurface region, which suppresses $\mathrm{ZnO}$ nanowire formation by blocking the supply of $\mathrm{Zn}$ atoms from the brass substrate.
\end{abstract}

KEYWORDS: Brass, ZnO, Nanowires, Oxidation, Sandblasting.

\section{INTRODUCTION}

As a typical wide band gap semiconductor, zinc oxide $(\mathrm{ZnO})$ nanostructures have attracted extensively attention due to promising potentials in many applications such as gas sensors, ${ }^{1}$ catalysts, ${ }^{2}$ UV lasers, ${ }^{3}$ field emitters, ${ }^{4}$ solar cells, ${ }^{5}$ hydrogen-storage devices, ${ }^{6}$ and field effect transistors. ${ }^{7}$ Various approaches, including vaporsolid (VS), vapor-liquid-solid (VLS), epitaxial growth, hydrothermal, and other solution processes have been used to produce all kinds of $\mathrm{ZnO}$ nanostructures. But from the technological point of view, preparation of $\mathrm{ZnO}$ nanostructures by direct thermal oxidation of $\mathrm{Zn}$ is a simple and low cost approach, ${ }^{8-11}$ which makes it an attractive synthesis route for the elimination of many complex multistage processes of catalytic chemical synthesis that involves many intermediaries. $\mathrm{ZnO}$ nanostructures have thus been synthesized successfully by directly heating zinc foils, ${ }^{9,12}$ brass, ${ }^{10,11,13} \mathrm{Zn}$ thin film on top of other substrates, such as $\mathrm{Si}^{14}{ }^{14} \mathrm{CdTe}^{15}$ and sapphire. ${ }^{16}$ Compared to the low melting point of zinc foil and $\mathrm{Zn}$ thin film $\left(\sim 420{ }^{\circ} \mathrm{C}\right)$, brass with a $\mathrm{Zn}$ content less than $35 \%$ has a much higher melting temperature $\left(\sim 900{ }^{\circ} \mathrm{C}\right),{ }^{17}$ which is good for the formation and application of $\mathrm{ZnO}$ nanostructures at elevated temperatures without the necessity of involving melted $\mathrm{Zn}$.

Sandblasting is a common mechanical procedure providing repeated impacts on a surface at a high speed which

\footnotetext{
*Author to whom correspondence should be addressed.

Email: gzhou@binghamton.edu

Received: 1 September 2012

Accepted: 2 September 2012
}

is widely used in metal and alloy treatment. It has been reported that the sandblasting can generate compressive residual stresses and high-density dislocations in the target substrate, resulting in the formation of nanocrystalline structures on the surface. ${ }^{18,19}$ In the present work, the effect of sandblasting on the oxidation process of brass has been studied. It is shown that the increased sandblasting leads to the gradual suppression of $\mathrm{ZnO}$ formation. The resulting surface morphologies of the sandblasted samples have been characterized by optical profiler and scanning electron microscopy (SEM). The composition and structure of the $\mathrm{ZnO}$ nanowires and oxide layer have been analyzed by X-ray diffraction (XRD) and X-ray photoelectron spectroscopy (XPS). Sputter etching is combined with XPS to detect the evolution of composition of the oxide layer in different depths.

\section{EXPERIMENTAL DETAILS}

High-purity brass $\left(\mathrm{Cu}_{0.7} \mathrm{Zn}_{0.3}\right.$ alloy) substrates (99.98\%) with a thickness of $0.25 \mathrm{~mm}$ are used for the oxidation experiments. The brass foils are first sandblasted by abrasive glass beads with diameter range of 150 250 $\mu \mathrm{m}$ at $\sim 100$ psi with different durations to generate different surface roughness. The surface roughness of sandblasted brass samples is measured using an optical profiler (WYKO NT1100). After sandblasting, the brass sheets are cut into approximately $1 \mathrm{~cm} \times 1 \mathrm{~cm}$ pieces and then thoroughly rinsed with deionized water followed by ultrasonication in acetone for $5 \mathrm{~min}$. The cleaned brass substrates are dried in $\mathrm{N}_{2}$ and then placed on a substrate 
heater in a vacuum chamber, where the sample temperature is monitored using a $K$-type thermocouple in contact with the substrate heater. The oxidation loading apparatus is large enough so that the brass specimens with different surface roughness can be loaded simultaneously and then oxidized under the same oxidation conditions. The oxidation chamber is first pumped to vacuum $(\sim 2 \times$ $10^{-4}$ Torr), and then filled with 220 mbar oxygen pressure (the purity of oxygen is $99.999 \%$ ). The chamber is then sealed and the brass samples are heated to $350{ }^{\circ} \mathrm{C}$ at the rate of $\sim 20{ }^{\circ} \mathrm{C} / \mathrm{min}$ and oxidized at the temperature for $1 \mathrm{~h}$. It is then cooled down in the same oxygen atmosphere to room temperature at the rate of $\sim 10{ }^{\circ} \mathrm{C} / \mathrm{min}$. Growth morphology and chemical composition of the oxidized samples are examined using field emission scanning electron microscopy (FEG-SEM, FEI Supra 55VP), energy-dispersive X-ray spectroscopy (EDS), and X-ray diffraction (XRD, PANalytical's X'Pert). Cross-sectional SEM samples are prepared by a cross-section polisher for analyzing the thickness of the oxide layer formed on the sandblasted brass substrates.

\section{EXPERIMENTAL RESULTS}

Figures 1(a)-(e) show the optical profiler 3D surface morphology of the brass substrates after being sandblasted with the different durations. It can be seen that the substrate without sandblasting has relatively smooth surface. Sandblasting for $3 \mathrm{~s}$ creates some craters with diameter about $200 \mu \mathrm{m}$ on the sample surface. The number of craters increases and the surface becomes rougher when the sandblasting time is increased to $5 \mathrm{~s}$. However, continuing sandblasting makes the substrates smoothening again due to overlapping of craters, as revealed in Figure 1(e).
The surface roughness of the brass substrates as a function of the sandblasting time is plotted in Figure 1(f). It can be seen that surface roughness increases with increasing the sandblasting time up to $5 \mathrm{~s}$, and then decreases with the further sandblasting.

The sandblasted samples with the different surface roughness as shown in Figure 1 are then oxidized simultaneously under the same condition at the temperature of $350{ }^{\circ} \mathrm{C}$ and oxygen pressure of 220 mbar for $1 \mathrm{~h}$. Figure 2(a) shows the typical surface morphology of the flat sample (sandblasting for $0 \mathrm{~s}$ ) after oxidation. Interlaced bright and dark regions are observed, and Figures 2(b) and (c) show, respectively, zoomed-in SEM images from these surface regions. As can be seen in Figure 2(b), the bright regions are covered with a high density of nanowires with a length of several hundred nanometers and a diameter of 30-60 nm. However, in dark regions, no nanowires or very few are observed. The chemical compositions of the bright and dark regions are measured by EDS and are shown in Figures 2(d) and (e). It can be seen that the bright regions have a higher composition for $\mathrm{Zn}$ than $\mathrm{Cu}$, while for the dark regions, the composition for $\mathrm{Cu}$ is higher than $\mathrm{Zn}$. Combined SEM imaging and EDS analysis of the different surface regions reveal that the bright regions with a high density of nanowires are $\mathrm{Zn}$-rich, while the dark regions without nanowire growth are $\mathrm{Cu}$-rich.

The surface morphologies of the oxidized brass samples sandblasted for the different durations are compared in Figure 3. Figure 3(a) shows the typical surface morphology of the bright regions on a flat sample. Figures 3(b)-(e) show the surface morphology of the samples sandblasted for $3,5,7,9 \mathrm{~s}$, respectively. It can be seen apparently that the surface density of nanowires decreases gradually with increasing the sandblasting time, and the substrate sandblasted for $9 \mathrm{~s}$ show barely nanowire formation.
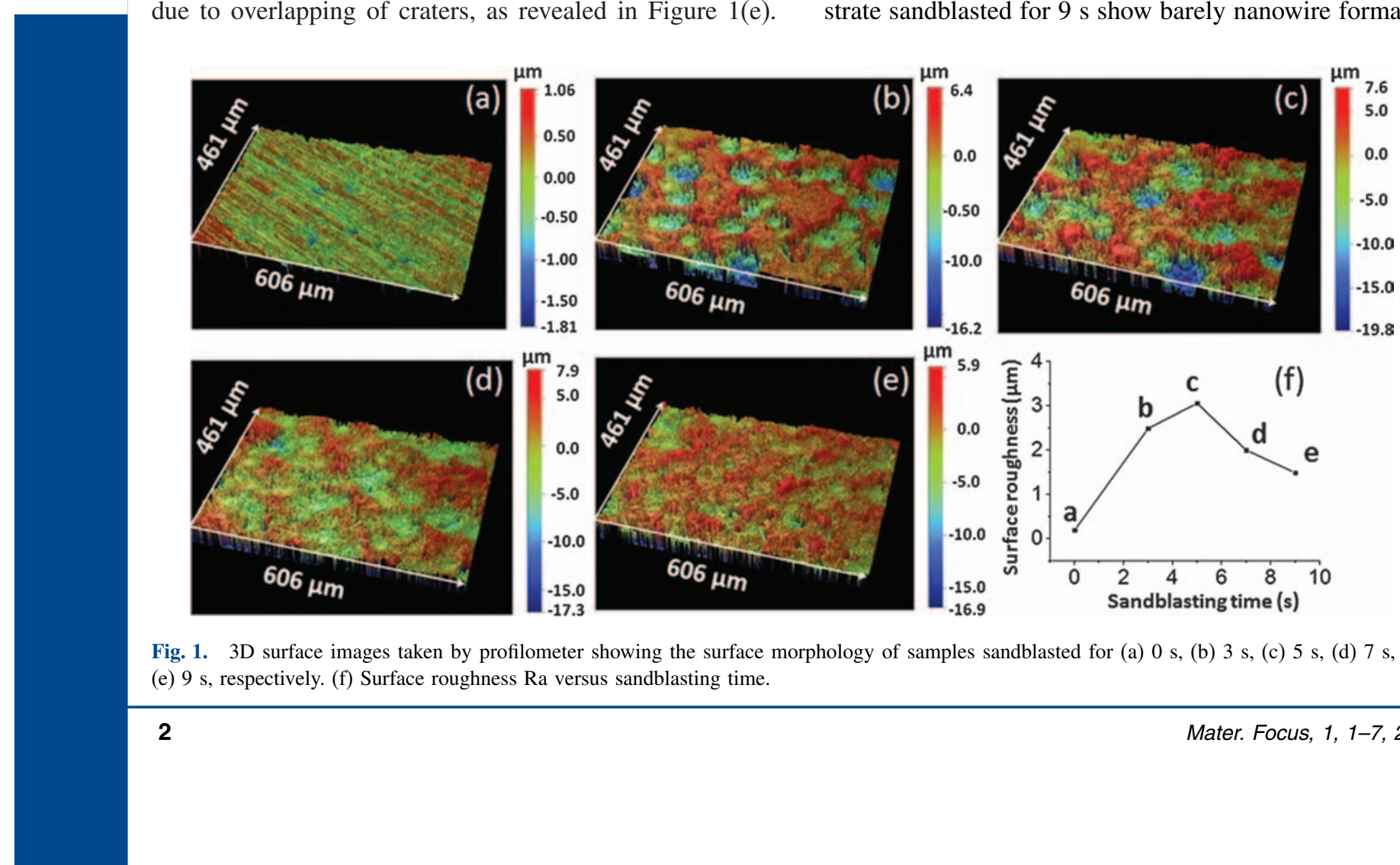

Fig. 1. 3D surface images taken by profilometer showing the surface morphology of samples sandblasted for (a) $0 \mathrm{~s}$, (b) $3 \mathrm{~s}$, (c) $5 \mathrm{~s}$, (d) $7 \mathrm{~s}$, and (e) 9 s, respectively. (f) Surface roughness Ra versus sandblasting time. 

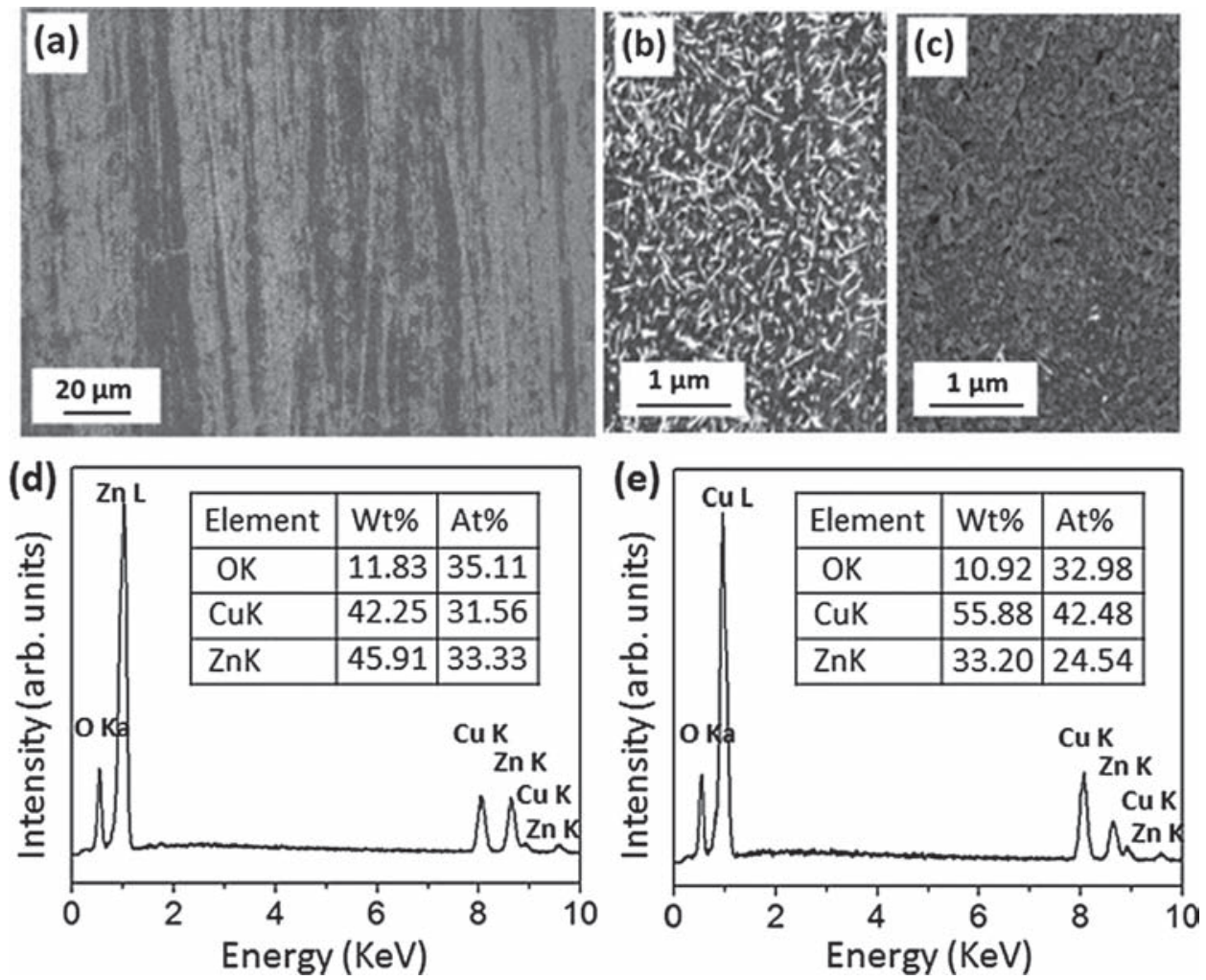

Fig. 2. (a) Flat brass substrate oxidized at 220 mbar, $350 \mathrm{C}$ for $1 \mathrm{~h}$; (b) and (c) are high magnification SEM images from the white and black areas of (a); (d) and (e) are the EDS patterns collected from (b) and (c), respectively.

The density of nanowires is measured from the SEM images obtained from different surface regions and Figure 3(f) shows the evolution of the surface density of nanowires as a function of the sandblasting time. It is also noticed that the sandblasted samples have rough surface compared to flat sample and the border regions of bright areas ( $\mathrm{Zn}$-rich) and dark areas ( $\mathrm{Cu}$-rich) become undistinguishable with increasing the sandblasting time.
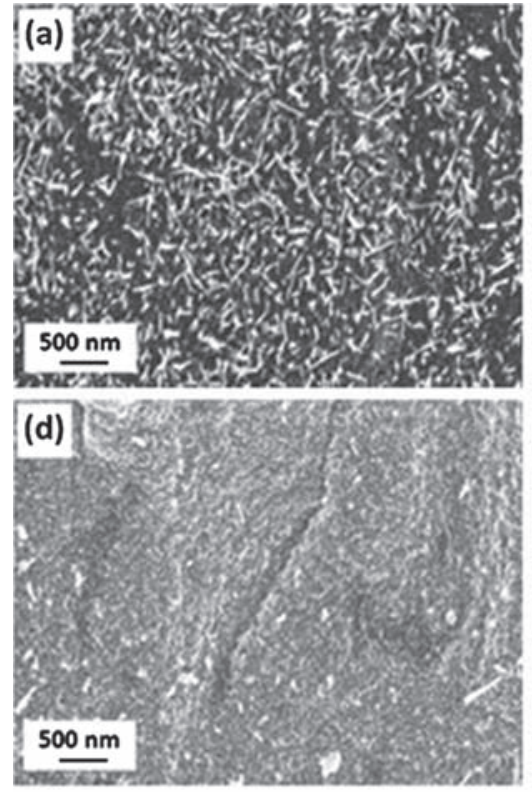
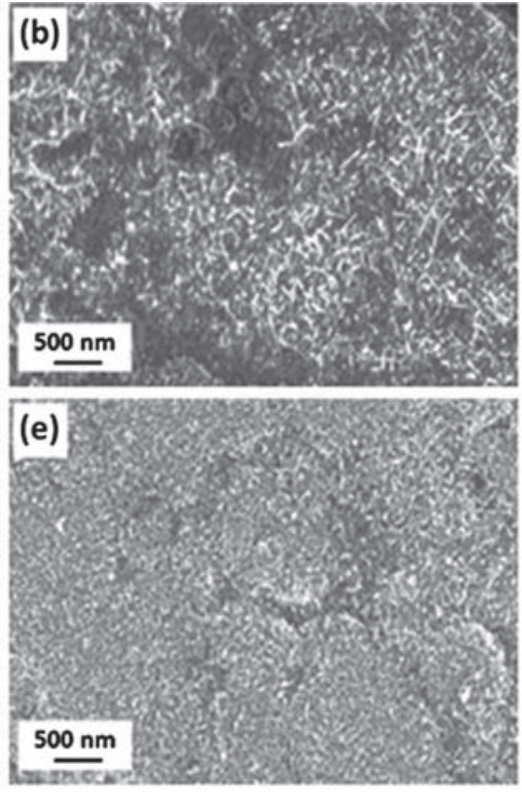
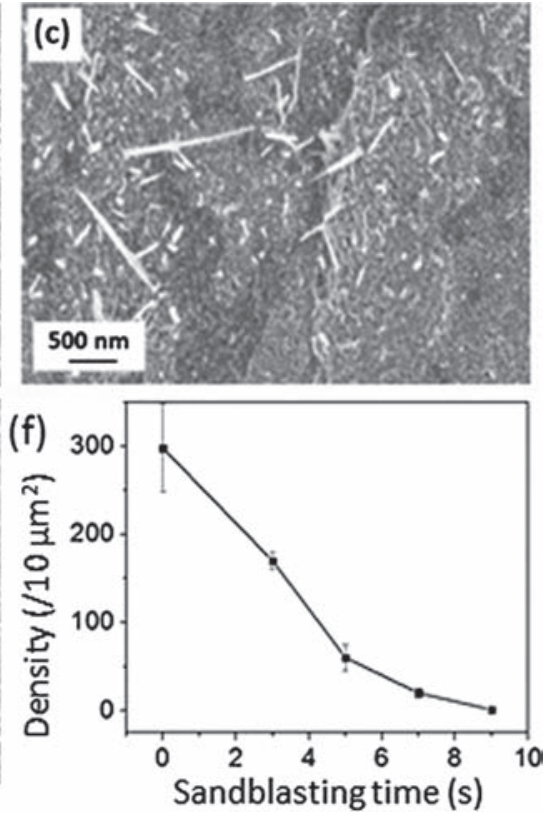

Fig. 3. Surface morphology of oxidized brass samples being sandblasted for (a) $0 \mathrm{~s}$, (b) $3 \mathrm{~s}$, (c) $5 \mathrm{~s}$, (d) $7 \mathrm{~s}$ and (e) 9 s, respectively; (f) Surface density of $\mathrm{ZnO}$ nanowires as a function of oxidation time. 

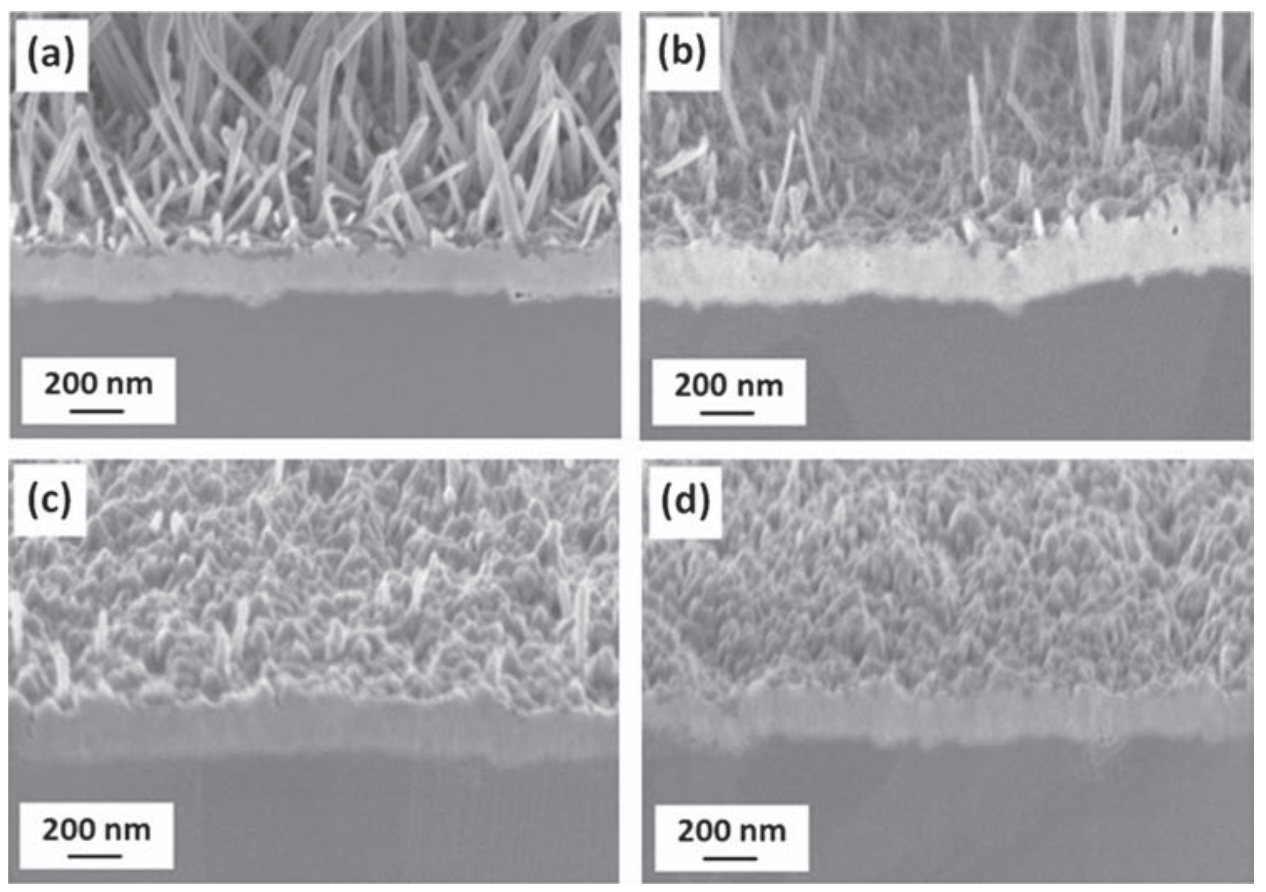

Fig. 4. Cross-sectional SEM images of samples sandblasting for (a) $0 \mathrm{~s}$; (b) $5 \mathrm{~s}$; (c) $7 \mathrm{~s}$; (d) 9 s, respectively. The surface density of the nanowires decreases with increasing the sandblasting time.

Cross-section interfacial samples were made from the oxidized samples using a cross section polisher. Figure 4 shows the interfacial SEM images obtained from the brass samples sandblasted for the different durations, which shows clearly that the oxidation results in the growth of an oxide layer on the brass substrates with nanowire formation on the oxide layer. It can be seen that the brass sample without sandblasting shows the growth of high density of long nanowires. The nanowire density decreases with increasing the sandblasting time. These growth features confirm the SEM surface views of the samples as shown in Figure 3. It can be also noticed from Figure 4 that the oxide layer is relatively uniform with a thickness of about $200 \mathrm{~nm}$, and there is no obvious difference in the oxide thickness for the brass samples sandblasted for the different durations.

XRD was used to determine the structural and phase evolution of the oxide layer and nanowires from the oxidation of the brass samples. Figure 5 shows XRD patterns from the flat sample and the sample sandblasted for $9 \mathrm{~s}$. As can be seen, almost all remarkable peaks can be ascribed to the brass structure. Several weak $\mathrm{ZnO}$ peaks are visible for the growth of the $\mathrm{ZnO}$ layer and $\mathrm{ZnO}$ nanowires. The weak intensity of the $\mathrm{ZnO}$ peaks is due to the thin thickness of the $\mathrm{ZnO}$ layer $(\sim 200 \mathrm{~nm})$. There is no sign showing the peaks of $\mathrm{CuO}$, which suggests there is no $\mathrm{CuO}$ or very little $\mathrm{CuO}$ formed.

XPS is very sensitive to surface chemical composition and is thus employed to measure the phase purity and the chemical composition of the oxidized brass samples. The survey and the high-resolution scanning XPS spectra of the samples are shown in Figure 6. Figure 6(a) shows the survey scan of the flat brass sample, which reveals the core level photoemission peaks corresponding to zinc, copper, oxygen and carbon only. Figures 6(b)-(d) depict the detailed scan for the $\mathrm{Zn}-2 \mathrm{p} 3, \mathrm{Cu}-2 \mathrm{p} 3$, and $\mathrm{O}-1 \mathrm{~s}$ regions of the samples sandblasted for the different duration. The $\mathrm{Zn}-2 \mathrm{p} 3$ peak located at $1021.7 \mathrm{eV}$ shown in Figure 6(b) indicates that the zinc is in the form of $\mathrm{ZnO}$ oxide. ${ }^{20}$ The intensity of the $\mathrm{Zn}-2 \mathrm{p} 3$ peak from the different samples does not show much difference. From Figure 6(c), it is

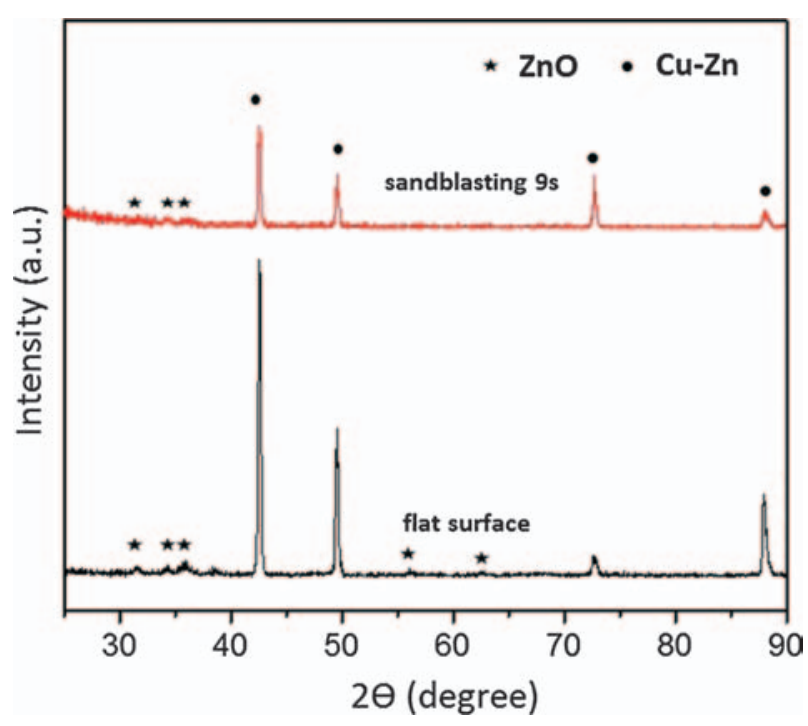

Fig. 5. XRD pattern obtained from the oxidized flat sample and sample undergone sandblasting for $9 \mathrm{~s}$. 

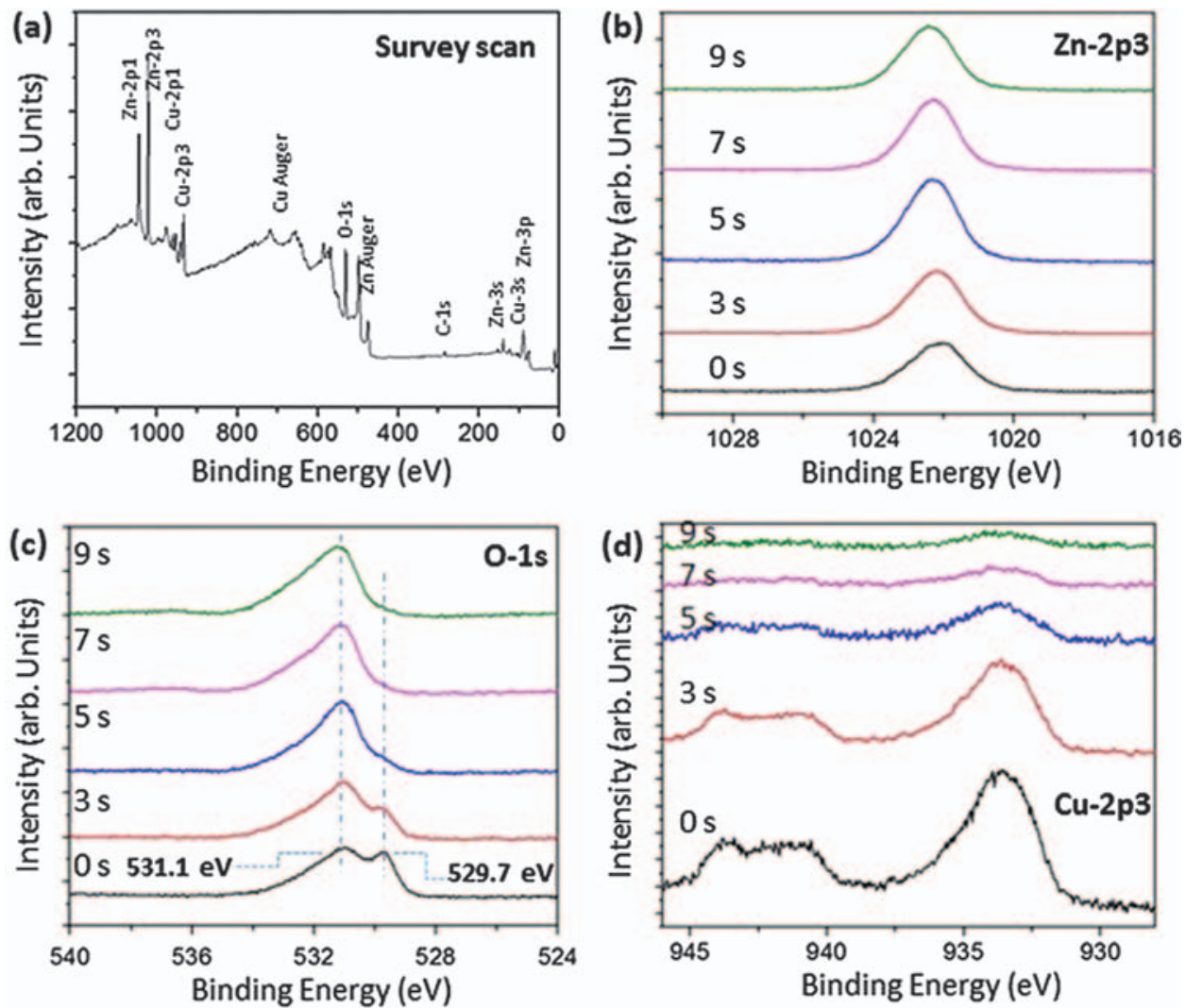

Fig. 6. XPS spectra of the oxidized brass samples sandblasted for different durations: (a) survey scan of the flat brass substrate; (b) Zn-2p3 region (c) O-1s region, (d) Cu-2p3 region of samples sandblasting for different times.

clear that there are two peaks corresponding to O-1s. It can be seen that the evolution of the relative intensities of the two O-1s peaks shows clear dependence with the sandblasting time. The first one located at $531.1 \mathrm{eV}$ is related to $\mathrm{O}^{2-}$ in the wurtzite structure of $\mathrm{ZnO}$, and the second one located at $529.7 \mathrm{eV}$ can be assigned to $\mathrm{O}^{2-}$ in $\mathrm{CuO}^{20}$ It can be also seen that the intensity of the O-1s peak associated with the $\mathrm{CuO}$ phase is very weak, suggesting the formation of very tiny amount of $\mathrm{CuO}$. This is consistent with the XRD analysis as shown in Figure 5, where the amount of the $\mathrm{CuO}$ phase is too little to detect by the XRD. With increasing the sandblasting time, the intensity of the O-1s peak at $531.1 \mathrm{eV}$ increases while the intensity of the O-1s peak at $529.7 \mathrm{eV}$ decreases. Such a correlation

Table I. Relative peak intensity and surface composition from XPS measurements on the oxidized brass samples sandblasted for different durations.

\begin{tabular}{lccccc}
\hline $\begin{array}{l}\text { Sandblasting } \\
\text { time (sec) }\end{array}$ & $\mathrm{Zn}$ & $\mathrm{O}$ & $\mathrm{Cu}$ & $\mathrm{C}$ & $\mathrm{Cu} / \mathrm{Zn}$ \\
\hline 0 & 25.5 & 49.5 & 16.8 & 8.1 & 0.659 \\
3 & 31.4 & 49.5 & 10.9 & 8.2 & 0.347 \\
5 & 38.9 & 50.2 & 4.8 & 6.1 & 0.123 \\
7 & 35.1 & 53.3 & 2.4 & 9.2 & 0.068 \\
9 & 30.4 & 58.2 & 2.2 & 9.5 & 0.072 \\
\hline
\end{tabular}

suggests that the continued sandblasting promotes the formation of the $\mathrm{ZnO}$ phase while suppressing the growth of the $\mathrm{CuO}$ phase. Figure 6(d) shows the $\mathrm{Cu}-2 \mathrm{p} 3$ peak, its binding energy located at $933.7 \mathrm{eV}$ indicates that the copper is in the form of $\mathrm{CuO}$ oxide. It shows clearly that the intensity of the $\mathrm{Cu}-2 \mathrm{p} 3$ peak decreases with increasing the sandblasting time, suggesting that formation of the $\mathrm{CuO}$ phase is suppressed with the sandblasting. This is consistent with the evolution of the O-1s peak associated with the $\mathrm{CuO}$ phase as shown in Figure 6(c). The intensities of the XPS spectra are converted to element concentrations ratios given in Table $\mathrm{I}$, which shows clearly that the relative intensity of $\mathrm{Cu} / \mathrm{Zn}$ decreases with increasing the sandblasting time and demonstrates that the sandblasting enhances the surface composition of $\mathrm{Zn}$ in the oxidized brass samples. It can be also seen that carbon impurity is also present and its composition is relatively consistent in the different brass samples.

\section{DISCUSSION}

The first study of high temperature oxidation of $\mathrm{Cu}-\mathrm{Zn}$ alloy can be dated back to 1931, and detailed study since then has showed that there is only $\mathrm{ZnO}$ formation in the brass systems of less than $76 \% \mathrm{Cu}^{21}$ According to the recent published work, ${ }^{22-24} \mathrm{Cu}_{70} \mathrm{Zn}_{30}$ oxidized at 

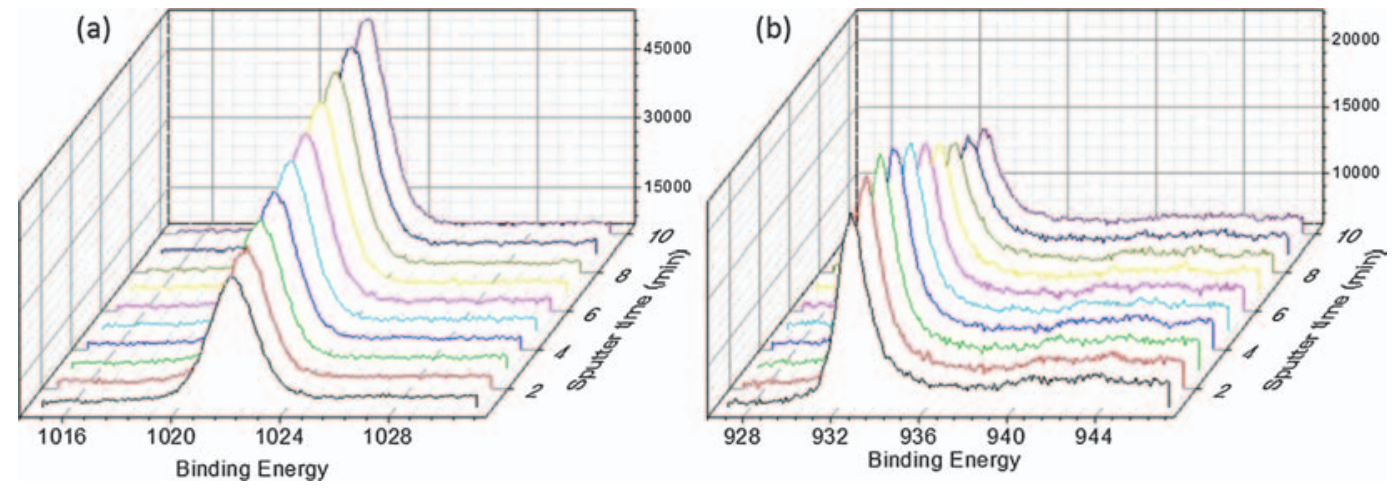

Fig. 7. XPS depth profile analysis of the oxidized brass sample (the flat sample) using ion-sputtering to remove the material from the surface: the spectra of (a) $\mathrm{Zn}-2 \mathrm{p} 3$ and (b) $\mathrm{Cu}-2 \mathrm{p} 3$ as a function of the ion puttering time.

$350{ }^{\circ} \mathrm{C}$ and 220 mbar should form zinc oxide only. Even though a small amount of $\mathrm{Cu}$ may be oxidized to form $\mathrm{CuO}$ by chance, the newly formed $\mathrm{CuO}$ would be easily reduced back to pure $\mathrm{Cu}$ by the reaction of $\mathrm{Zn}+\mathrm{CuO}=$ $\mathrm{ZnO}+\mathrm{Cu} .{ }^{11}$ Such a reaction direction is thermodynamically favorable because of the lower free energy for the formation of $\mathrm{ZnO}$ compared to $\mathrm{CuO}$. However, in our case, the XPS results show clearly there are both $\mathrm{ZnO}$ and $\mathrm{CuO}$ formed on the surface. We attribute to this difference compared to the earlier studies to the uneven surface composition of the brass samples, which show $\mathrm{Zn}$-rich and $\mathrm{Cu}$-rich regions, as demonstrated in Figure 2.

Once the brass samples are exposed to oxygen at the elevated temperature, both zinc in $\mathrm{Zn}$-rich regions and copper in $\mathrm{Cu}$-rich regions are oxidized to form discrete $\mathrm{ZnO}$ and $\mathrm{CuO}$ nuclei. As the oxidation continues, these oxide nuclei grow and coalesce to cover the entire surface to form a continuous oxide film containing both zinc oxide and copper oxide. The direct contact of $\mathrm{CuO}$ and $\mathrm{ZnO}$ grains in the oxide film results in the reaction of $\mathrm{Zn}+\mathrm{CuO}=\mathrm{ZnO}+\mathrm{Cu}$ since $\mathrm{ZnO}$ is more stable than $\mathrm{CuO}$. Thus, $\mathrm{CuO}$ is decomposed into pure $\mathrm{Cu}$ with the formation of $\mathrm{ZnO}$, where the pure $\mathrm{Cu}$ is gradually buried in the subsurface region by the $\mathrm{ZnO}$ layer with the continued oxidation. For the present experiments, the oxidation temperature is relatively low $\left(350{ }^{\circ} \mathrm{C}\right)$ and the oxidation time is short $(1 \mathrm{~h})$. There is still some remaining $\mathrm{CuO}$ in the $\mathrm{Cu}$-rich area. This can explain why there is copper oxide detected by XPS.

Even though the $\mathrm{CuO}$ phase is detected by XPS, there are no $\mathrm{CuO}$ diffraction peaks visible in the XRD pattern. This suggests that the $\mathrm{CuO}$ phase is little and it is mostly formed on the top surface of the sample as it is detected by XPS. The difference between the XRD and XPS results shown above can be attributed to the difference in depth profiling of each technique: XRD gives characteristic of the bulk materials while XPS shows the surface information in the range of few nanometers. ${ }^{25}$ To confirm the above speculation, the oxidized brass sample is sputtered for 10 cycles for $10 \mathrm{~min}$ at the voltage of $2 \mathrm{kV}$. The sputtering rate is taken $\mathrm{SiO}_{2}$ as a reference $(5.9 \mathrm{~nm} / \mathrm{min}$ for
$\mathrm{SiO}_{2}$ ). As shown in Figure 7, the intensity of the $\mathrm{Zn}-2 \mathrm{p} 3$ peak increases with increasing the sputtering time, while the intensity of the $\mathrm{Cu}-2 \mathrm{p} 3$ peak increases at first and then decreases. The initial increase in the intensity of the $\mathrm{Cu}-2 \mathrm{p} 3$ peak is due to the removal of the $\mathrm{ZnO}$ nanowire layer by sputtering. With continued removal of the surface material by sputtering, the intensity of the $\mathrm{Cu}-2 \mathrm{p} 3$ peak decreases while that of the $\mathrm{Zn}-2 \mathrm{p} 3$ peak increases due to the presence of more $\mathrm{ZnO}$ in the underlying $\mathrm{ZnO}$ layer. The intensity evolution of the $\mathrm{Cu}-2 \mathrm{p} 3$ and $\mathrm{Zn}-2 \mathrm{p} 3$ peaks as a function of the surface depth demonstrates clearly that the amount of the $\mathrm{CuO}$ phase decreases while that of the $\mathrm{ZnO}$ phase increases from the surface to the subsurface region.

By exerting sandblasting on the surface, the initially uneven surface composition of the brass substrates can be changed to even due to the formation of nanocrystalline structures on the surface. The longer sandblasting time results in better mixed $\mathrm{Zn}$-rich and $\mathrm{Cu}$-rich regions with the shrinkage of $\mathrm{Cu}$-rich regions. Therefore, $\mathrm{CuO}$ nuclei form more uniformly on the surface and thus finer $\mathrm{CuO}$ grains in the coalesced oxide layer compared to the oxidation of un-sandblasted surface that is expected to result in larger $\mathrm{CuO}$ grains in $\mathrm{Cu}$-rich regions. Upon the continued oxidation, these tiny $\mathrm{CuO}$ grains can be easily reduced by outward diffusing $\mathrm{Zn}$ to form pure $\mathrm{Cu}$ and $\mathrm{ZnO}$. This explains why the intensity of the $\mathrm{Zn}-2 \mathrm{p} 3$ peak increases while that of the $\mathrm{Cu}-2 \mathrm{p} 3$ peak decreases with increasing the sandblasting time. Since the increased sandblasting improves the uniform distribution of initially formed $\mathrm{CuO}$ nuclei, the subsequent reduction of fine $\mathrm{CuO}$ grains by $\mathrm{Zn}$ upon the further oxidation results in the formation of pure $\mathrm{Cu}$ which is accumulated more uniformly in the subsurface region. The formation of $\mathrm{ZnO}$ nanowires requires continuous supply of $\mathrm{Zn}$ atoms from the brass substrate. However, the formation of pure $\mathrm{Cu}$ in the subsurface region blocks the supply of $\mathrm{Zn}$ and thus suppresses the formation of $\mathrm{ZnO}$ nanowires, as shown experimentally that the surface density of $\mathrm{ZnO}$ nanowires decreases with increasing the sandblasting time. 


\section{CONCLUSION}

We have studied the effect of sandblasting on the formation of $\mathrm{ZnO}$ nanowires during the thermal oxidation of brass. For the oxidation of un-sandblasted brass samples, there are Zn-rich regions, which are covered by high density of $\mathrm{ZnO}$ nanowires, and $\mathrm{Cu}$-rich regions, where no $\mathrm{ZnO}$ nanowires form. It is shown that the increase in the sandblasting time leads to the gradual suppression of $\mathrm{ZnO}$ nanowire formation across the entire surface. XPS depth profile analysis shows there are both $\mathrm{ZnO}$ and $\mathrm{CuO}$ formed on the oxide surface, but the quantity of the $\mathrm{CuO}$ phase decreases from the surface to subsurface region. This is because the $\mathrm{CuO}$ phase can be easily reduced to pure $\mathrm{Cu}$ by outward diffusing $\mathrm{Zn}$ at the high temperature. It is also found that the quantity of $\mathrm{CuO}$ formed on the surface decreases with increasing the sandblasting time. These results are due to the fact that the chemical composition of the brass substrate becomes more even with sandblasting, which leads to more uniform nucleation of $\mathrm{CuO}$ nuclei across the entire surface. The subsequent reduction of the $\mathrm{CuO}$ phase by $\mathrm{Zn}$ in the coalesced oxide layer correspondingly results in the uniformly accumulated pure $\mathrm{Cu}$ in the sublayer region, which suppresses $\mathrm{ZnO}$ nanowire formation by blocking the supply of $\mathrm{Zn}$ atoms from the brass substrate.

Acknowledgments: This work was supported by the National Science Foundation under the Grant No. CMMI0825737. We thank David Richner for access to the sandblasting equipment.

\section{References and Notes}

1. Q. Wan, Q. Li, Y. Chen, T. Wang, X. He, J. Li, and C. Lin, Appl. Phys. Lett. 84, 3654 (2004).

2. W. Xie, Z. Yang, and H. Chun, Ind. Eng. Chem. Res. 46, 7942 (2007).
3. J. C. Johnson, H. Yan, P. Yang, and R. J. Saykally, The Journal of Physical Chemistry B 107, 8816 (2003).

4. D. Banerjee, S. H. Jo, and Z. F. Ren, Adv. Mater. 16, 2028 (2004).

5. M. Law, L. E. Greene, J. C. Johnson, R. Saykally, and P. Yang, Nat. Mater. 4, 455 (2005).

6. H. Pan, J. Luo, H. Sun, Y. Feng, C. Poh, and J. Lin, Nanotechnology 17, 2963 (2006).

7. H. Yuan, H. Shimotani, A. Tsukazaki, A. Ohtomo, M. Kawasaki, and Y. Iwasa, Adv. Funct. Mater. 19, 1046 (2009).

8. S. Ren, Y. F. Bai, J. Chen, S. Z. Deng, N. S. Xu, Q. B. Wu, and S. Yang, Mater. Lett. 61, 666 (2007).

9. X. Wen, Y. Fang, Q. Pang, C. Yang, J. Wang, W. Ge, K. S. Wong, and S. Yang, J. Phys. Chem. B 109, 15303 (2005).

10. C. H. Xu, Z. B. Zhu, H. F. Lui, C. Surya, and S. Q. Shi, Superlattices Microstruct. 49, 408 (2011).

11. H. Kaifu, H. Yemin, F. Jijiang, W. Xuebin, C. Paul K., H. Zheng, and C. Yi, J. Phys. Chem. C 111, 5876 (2007).

12. H. Y. Dang, J. Wang, and S. S. Fan, Nanotechnology 14, 738 (2003).

13. Y. Zhu, C. H. Sow, T. Yu, Q. Zhao, P. Li, Z. Shen, D. Yu, and J. T. L. Thong, Adv. Funct. Mater. 16, 2415 (2006).

14. L.-C. Chao, C.-F. Lin, and C.-C. Liau, Vacuum 86, 295 (2011).

15. O. Martínez, V. Hortelano, J. Jiménez, J. L. Plaza, S. de Dios, J. Olvera, E. Diéguez, R. Fath, J. G. Lozano, T. Ben, D. González, and J. Mass, J. Alloys Compd. 509, 5400 (2011).

16. G.-H. Lee, Electronic Materials Letters 6, 155 (2010).

17. H. Okamoto, Desk handbook: phase diagrams for binary alloys, Asm International, Materials Park, OH (2000).

18. X. S. Guan, Z. F. Dong, and D. Y. Li, Nanotechnology 16, 2963 (2005).

19. I. Nikitin, I. Altenberger, H. J. Maier, and B. Scholtes, Mater. Sci. Eng. A 403, 318 (2005)

20. G. E. Muilenbenger, Handbook of X-Ray Photoelectron Spectroscopy (1979).

21. T. L. Barr and J. J. Hackenberg, Applications of Surface Science 10, 523 (1982).

22. X. C. Hua, L. Y. Liang, and S. S. Qian, High Temp. Mater. Proc. 30, 267 (2011).

23. C. H. Xu, Z. B. Zhu, G. L. Li, W. R. Xu, and H. X. Huang, Mater. Chem. Phys. 124, 252 (2010).

24. F. Gao, S. Wang, F. Gesmundo, and Y. Niu, Oxid. Met. 69, 287 (2008).

25. F. Jamali-Sheini, K. R. Patil, D. S. Joag, and M. A. More, Appl. Surf. Sci. 257, 8366 (2011). 